Sandeep Alanka*, Chanamala Ratnam and Balla Srinivasa Prasad

\title{
An effective approach to synthesize carbon nanotube-reinforced Al matrix composite precursor
}

https://doi.org/10.1515/secm-2017-0229

Received July 3, 2017; accepted September 2, 2017; previously published online October 17, 2017

\begin{abstract}
Aluminum-based nanocomposites reinforced with carbon nanotubes have increased scientific attention in today's life. The dispersion quality was the critical aspect, which decides the homogeneous distribution of CNTs within the Al matrix as starting precursors. In this study, a new attempt has been made to obtain a uniformly dispersed Al-0.75\% CNT precursor via combining ultra-sonication, cubic tumbler rod milling, and spray drying. This process was integrated with organic deflocculant (formulator) in specific proportion to transform as a semi-wet-based route. The effect of milling media on the morphology and interface structure of the as-produced composite precursor after all the processing steps was investigated through scanning electron microscope (SEM), high-resolution transmission electron microscope (HRTEM), X-ray diffraction (XRD) analysis, Raman spectroscopy, and Fourier transform infrared spectroscopy. The results reveal that the approach is effective in CNT dispersion in $\mathrm{Al}$ precursor, which shields the nanotube structure from damage for longer periods of milling time due to the organic formulator mixture, and also, the CNT retention in the $\mathrm{Al}$ precursor with minimum clustering is identified compared to the ball milling process. Carbon traces were confirmed in the as-produced composite precursor by this approach.
\end{abstract}

Keywords: cubic tumbler rod milling; FTIR; nanocomposite; organic deflocculant (formulator); SEM; starting precursor; XRD.

\footnotetext{
*Corresponding author: Sandeep Alanka, Mechanical Engineering, GITAM University, Visakhapatnam-530045, India, Phone: +919866664036, e-mail: sandeep.alanka@gmail.com. http://orcid.org/0000-0003-0355-0801 Chanamala Ratnam: Mechanical Engineering, College of Engineering (A), Andhra University, Visakhapatnam-530003, India

Balla Srinivasa Prasad: Mechanical Engineering, GITAM University, Visakhapatnam-530045, India
}

\section{Introduction}

Composite material contains a matrix with one or more distributed phases. To obtain the desired properties compared with performance limitation of monolithic materials, it created a remarkable expansion from sports racket to space rocket and became an essential part of today's industries. In fact, most of the industries widely uses aluminum (Al)-based composite with their tailored properties, i.e. high specific strength, specific modulus, etc., to reach the advance developments $[1,2]$. The proposed carbon nanotubes (CNTs) as ideal reinforcements for Al-based composites due to the ultra-high strength, ultra-high Young's modulus, high thermal conductivity, weight reduction, and large aspect ratio for structural and functional applications $[3,4]$ have created an amount of scientific attention toward $\mathrm{Al}$ matrix nanocomposites. It was discussed that incorporation of the CNTs with metal or alloys exhibits the $\sim 1$-Tpa elastic modulus, 150-Gpa tensile strength, and excellent electrical and thermal conductivities $(\sim 6000 \mathrm{~W} / \mathrm{m}-\mathrm{K})$ with low CTE (CTE $\approx 0)$ [5-8].

However, a few major challenges in the field of the Al-CNT composite are clustering and agglomeration of the CNTs due to their attractive van der Waals interaction and H-bonds. As a result, it is difficult to obtain the homogeneous dispersion of the CNTs in the Al matrix. The CNT-Al contact interface is also crucial, resulting in the deterioration of composites properties and lack of suitable fabrication technique [9]. To overcome these challenges, various techniques have been suggested such as powder metallurgy [10-13], thermal spraying [14-16], and nanoscale dispersion [17]. Among these, powder metallurgy appears to be promising techniques owing to its simplicity, flexibility, and controllability [14, 18]. One of the common bottleneck in powder metallurgy is the CNTs' dispersion in starting $\mathrm{Al}$ powders, which is usually done by mechanical alloying/ball milling $[10,19]$ that affects the tubular damage, CNTs' distribution in the final Al-CNT composite product, and incorporating sufficient amount of CNTs in the Al matrix [3]. Until now, studies have reported on dispersing CNTs throughout the Al matrix powders either by dry powder blending or wet slurry 
blending leading to heterogeneous behavior due to size, shape, and morphology of used CNTs and Al powders [9]. Liu et al. [4] employed a high-energy mechanical alloying in a planetary ball mill as dry powder blending to disperse $\mathrm{Al}-0.5$ wt. $\%$ CNT with 1.8 wt. $\%$ process control agent at a speed of $300 \mathrm{rpm}$ using a ball to powder ratio of 8:1 for a milling time of $2-12 \mathrm{~h}$; however, better interfacial bonding is achieved after $6 \mathrm{~h}$ of milling, but the milling time extended from 8 to $12 \mathrm{~h}$ resulting in damage to the CNTs and destruction of their tubular structure. A similar case by Perez-Bustamante et al. [20] has been observed after $30 \mathrm{~h}$ of milling with transmission electron microscopy (TEM). At the same time, Esawi and EI Borady [21] confirmed that numerous CNT clusters were seen on the surface of the Al particles blended with X wt. \% CNT $(\mathrm{X}=0.5,1$, and 2$)$ prepared by low-energy mechanical alloying in a Turbula mixer at a rotary speed of $46 \mathrm{rpm}$, which leads to the ruin of the overall properties of the composites. Recently, the CNTs blended in solution are quite difficult to be absorbed on the Al powder surface due to the weak attractive force between the CNTs and Al, resulting in their $\zeta$ potential incompatibility, and weak Al-CNT bonding might result in agglomerates during dispersion in the slurry-based processes according to Chen et al. [22]. Simoes et al. [3] investigated the influence of the dispersion technique of the CNTs in producing $\mathrm{Al}$ matrix nanocomposites by three different routes. Among the three routes, the author has observed that the third route (R3) achieves better dispersion by ultra-sonication and mixing at 15-60 min. As a result, nanocomposites of 0.75 wt. \% of CNT exhibits well-dispersed and embedded nanotubes with higher hardness and tensile strength. Therefore, it appears to be a problem to produce $\mathrm{Al}$ CNT's starting powder by ball milling/wet slurry-based process, which was not satisfactory as an effect of prolonged milling time, tubular damage, Al-CNT's poor wettability, strong agglomeration of CNTs, and homogeneous dispersion of CNTs. In fact, the effective way to disperse the CNTs within the Al powder can be deeply affected by milling media and chemical modification of the surface of the Al powder. The organic agent on the wall of the CNTs is also discussed in this article.

The aim of the present research is to develop a new approach in processing an Al-0.75 wt. \% multi-walled carbon nanotube (MWCNT) composite with proper initiated steps of organic deflocculant (semi-wet state) to bind the starting powders via cubic tumbler rod mill (CTRM) (Orchid Scientifics, India) that can retain the CNTs in the $\mathrm{Al}$ matrix in their position, whereas it minimizes the structural damage and achieve a better dispersion of the CNTs in the nanocomposite.

\section{Materials and methods}

\subsection{Materials}

The procedure for the suggested approach of processing the Al-CNT starting precursor is shown in Figure 1. First, a precursor was prepared by combining ultra-sonication, CTRM, and spray dry with the objective of dispersing Al-0.75 wt. \% MWCNT composite in which MWCNTs are better distributed in the Al matrix. This precursor consists of gas-atomized $\mathrm{Al}$ powder with a size $\sim 40 \mu \mathrm{m}$, purity $99.7 \%$, produced by Otto Chemie Pvt Ltd, India, selected as the matrix constituent; CVD-grown MWCNTs of 20-30 nm OD, 10-30 $\mu \mathrm{m}$ length, purity $>95 \%$, supplied by Cheaptubes Inc, USA, as the reinforcement; and other organic deflocculants such as polyvinyl butyral (PVB), poly ethylene glycol (PEG; M.W. 300), and N,N-ethylene bis-stearamide (NN-EBS) supplied by Otto Chemie Pvt Ltd, India. Surface functionalization of the nanotubes was not done due to changes in the CNT structure [23].

\subsection{Methodology}

Initially, $150 \mathrm{ml}$ of isopropanol with the addition of $0.75 \mathrm{~g}$ of MWCNT was poured into a 500-ml glass beaker, which was then kept within ultrasonic bath (Cintex Industrial Corporation, India) and sonicated for $4 \mathrm{~h}$ to split entangled CNTs into individual tubes by frequency stir (power: $500 \mathrm{~W}$, frequency: $20 \mathrm{kHz}$ ). Meanwhile, $10 \mathrm{ml}$ of isopropanol was added to $99.25 \mathrm{~g}$ of Al powder in a cubic rod tumbler (Orchid Scientifics, India), milled for $20 \mathrm{~min}$ at a speed of $100 \mathrm{rpm}$ to make a flowable or fairly fluid system, which can easily be shaped and breaks down the agglomerates. The organic formulator was prepared separately with the grouping of $1 \mathrm{~g}$ of $\mathrm{PVB}$ as a binder, $0.5 \mathrm{~g}$ of PEG as a plasticizer, and $0.5 \mathrm{~g}$ of NN-EBS as a lubricant (organic mixture) added into the as-produced Al slurry, again milled for another $40 \mathrm{~min}$ at a speed of $80-100 \mathrm{rpm}$ to produce $\mathrm{Al}-2$ wt. \% organic formulator, which chemically modifies the surface of the Al powder and have the tendency to anchor and align MWCNT on the boundaries of Al particles.

Later, the as-prepared MWCNT suspension slurry was poured into the $\mathrm{Al}-2 \mathrm{wt}$ \% organic formulator (semi-wet state) for further milling using CTRM for $6 \mathrm{~h}$ at a speed of $100 \mathrm{rpm}$ to disperse the MWCNT in the Al matrix powder. The CTRM consists of an agitator between the cubical chambers, which prevents the CNT to agglomerate by imparting Al-CNTs onto the walls of the blender as well 


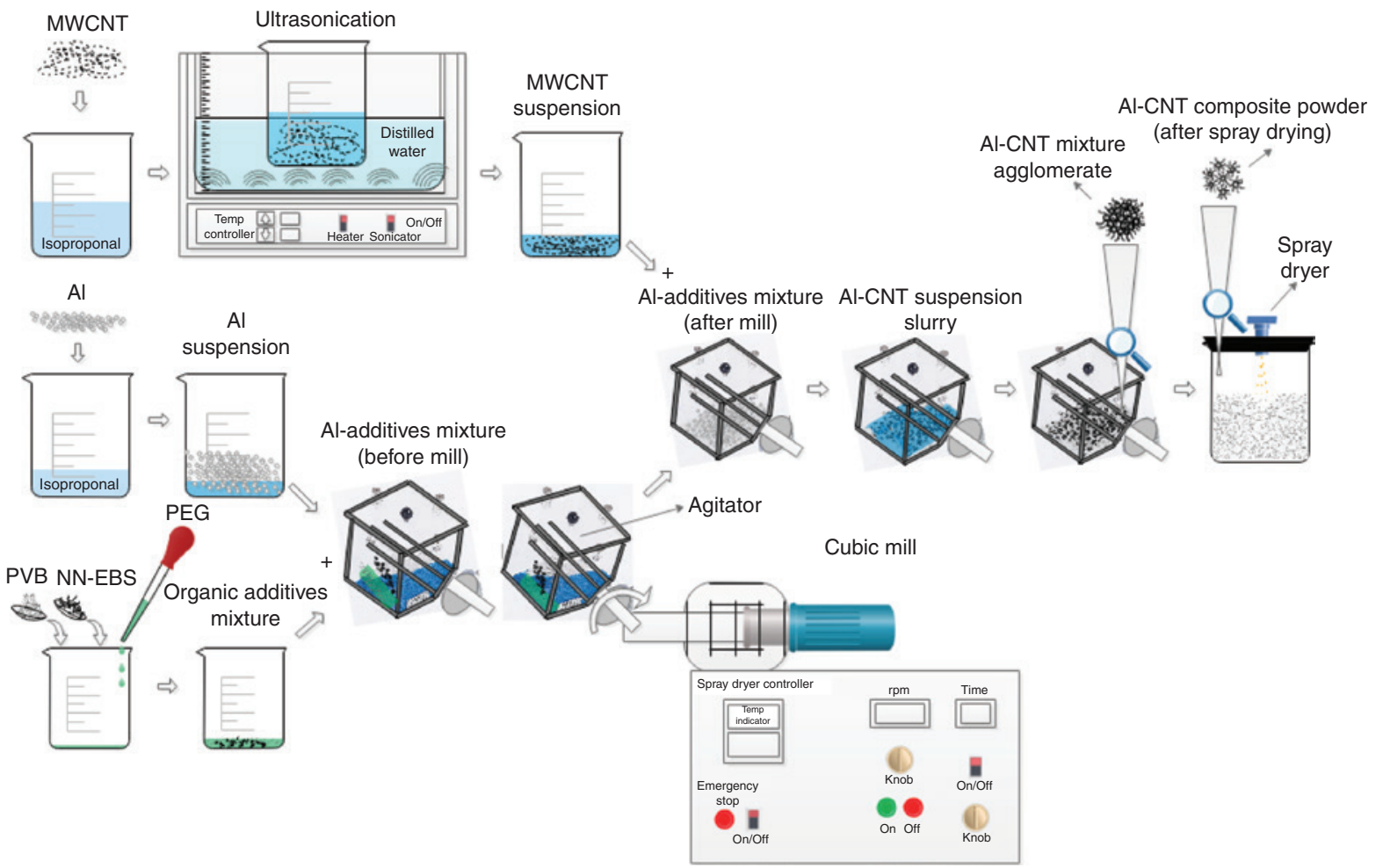

Figure 1: Schematic illustration of the processing procedure for Al- MWCNT composites.

as the agitator while going through the milling process, helping in the better dispersion of the composite mixture and retaining the MWCNT and Al particles in the actual state. Finally, the as-blended Al-CNT composite powder was spray dried at $\leq 200^{\circ} \mathrm{C}$ inlet air temperature for $30 \mathrm{~min}$ to evaporate the solvent and burn out the organic formulator from the Al-0.75 wt. \% MWCNT composite precursor. Then, the final Al-CNT composite precursor was further investigated for the study.

\subsection{Characterization}

The morphology of the final Al-CNT composite precursors was characterized using a JEOL (Japan), JSM6610LV scanning electron microscope (SEM) operated at voltage of $10-20 \mathrm{kV}$ to analyze the various samples under different magnifications. The microstructure of the raw CNT was investigated using a JEOL (Japan), JEM-2100 high-resolution transmission electron microscope (HRTEM) at an acceleration voltage of $200 \mathrm{keV}$. The TEM samples were prepared by focused ion beam (FIB) in a JEOL (Japan) JEM 9320-FIB microscope operated at $30 \mathrm{kV}$ and $25 \mathrm{~mA}$. On the other hand, X-ray diffraction (XRD) analysis of the powders were carried out in a PanAlytical X-Pert PRO diffractometer, Netherlands, with $\mathrm{Cu} \mathrm{K} \alpha$ radiation $(\lambda=1.5406 \AA)$ operated at a voltage of $40 \mathrm{kV}$ and a current of $35 \mathrm{~mA}$ in the $2 \theta$ range of $5-90^{\circ}$. XRD was used to find new phases produced during the different stages of synthesizing bulk specimens. The structural integrity of CNTs in the composites in various processes was characterized by Raman spectroscopy (Laser Micro Raman System) Horiba Jobin Vyon (Japan), LabRam HR. Finally, IR Prestige-21, Shimadzu (Japan), Fourier transform infrared (FTIR) spectroscopy was used for analyzing the surface functional groups on the MWCNT.

\section{Results and discussion}

The morphology of the as-received $\mathrm{Al}$ powders is shown in Figure 2A, B. In Figure 2A, it is clear that the shapes of the as-received $\mathrm{Al}$ particles are asymmetrical, which is helpful in the anchoring of MWCNTs onto the surface of the Al particles. Also, under high magnification, the $\mathrm{Al}$ particles that are observed in Figure $2 \mathrm{~B}$ have surfaces that are smooth having the advantage of better compaction and simplification of the particle friction as well as the die wall friction. Figure 3A, B shows the morphology 

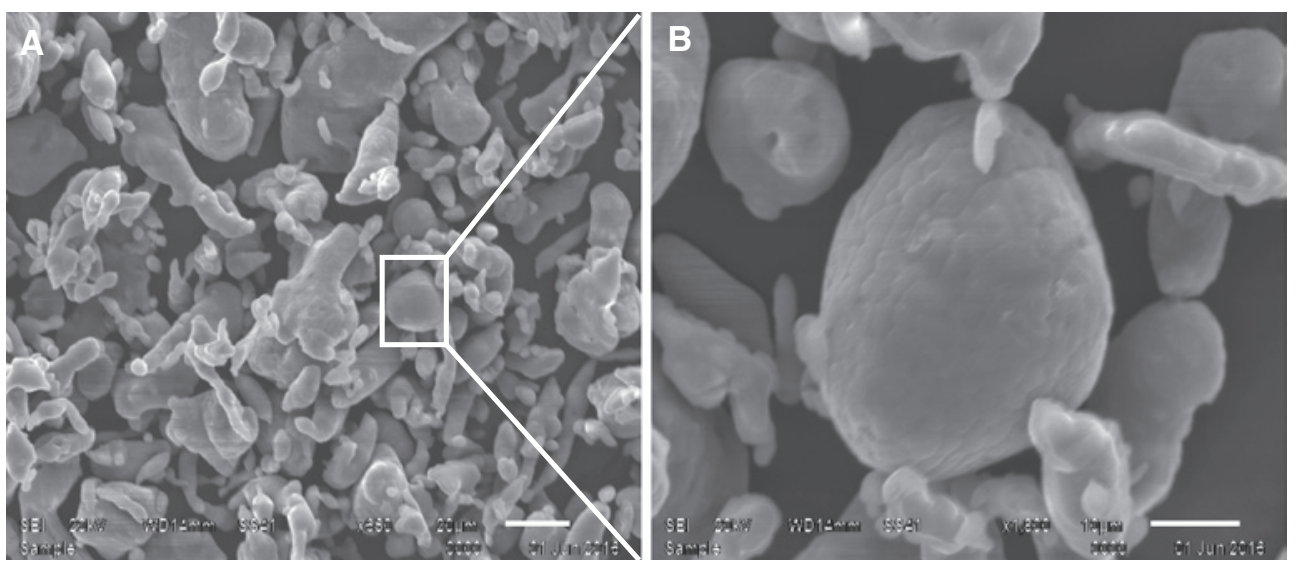

Figure 2: SEM images of (A) as-received Al powder at $20 \mu \mathrm{m}$; (B) under the magnification of $10 \mu \mathrm{m}$.
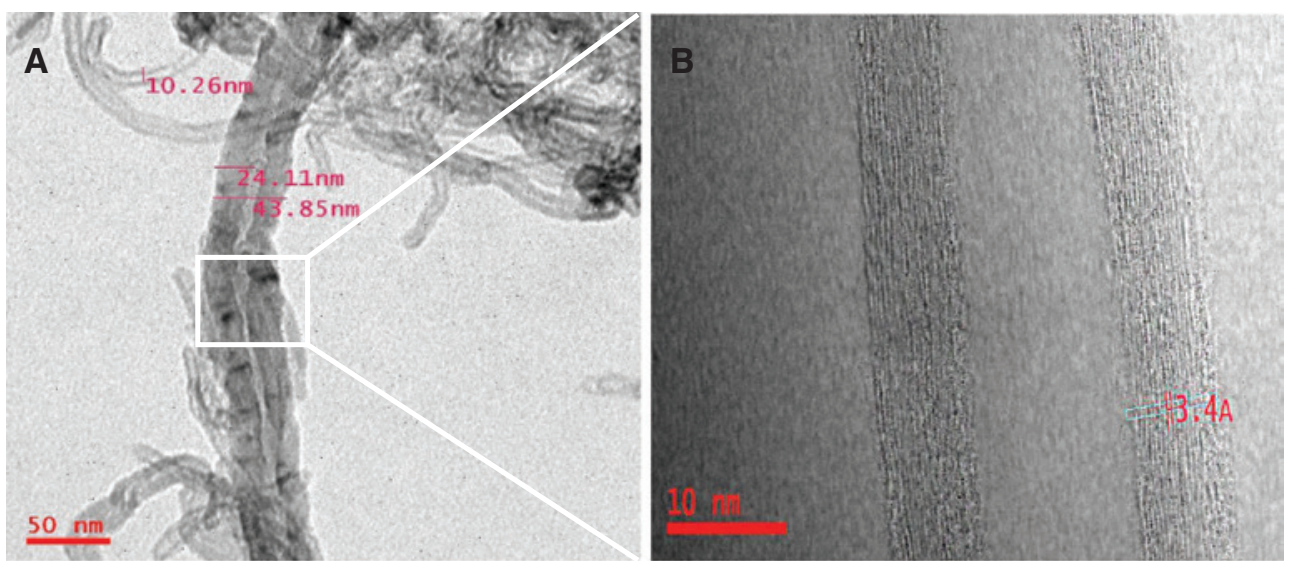

Figure 3: (A) TEM images of as-received MWCNTs at $50 \mathrm{~nm}$; (B) high-resolution TEM image of MWCNT screening multi-walls.

of the as-received MWCNTs, with long tubular structure and diameter, which has the tendency to produce clusters and agglomerate and then curved and entangled CNTs as proclaimed by Simoes et al. [3]. The image of the high-resolution transmission electron microscope (HRTEM) shows the multi-walls, which represent the MWCNTs as shown in Figure 3B. It is likely to view the presence of 26 walls, and the average inner diameter of the CNT is measured as $3.4 \pm 1 \mathrm{~nm}$. From the TEM observations, the average outer diameter of the raw CNTs was measured as $24.11 \pm 4 \mathrm{~nm}$, respectively.

The dispersion of the CNT using high-energy ball milling was confirmed to be unsuccessful because longer periods of time, excessive cold weld, and decrease in length, damage the CNT structure [20]. Simoes et al. [23] prefer isopropanol as a solvent to CNT to avoid the structural changes, which may be effected by ethanol. Instead, an ultra-sonicator was used as an effective way to disperse the CNT agglomerate for $4 \mathrm{~h}$ and to untangle the CNT.
Figure 4A shows the SEM image of Al- 0.75 wt. \% of MWCNT composite powder produced by CTRM via adding 2 wt. \% of organic formulator mixture. It is seen that micro-sized Al powder was agglomerated due to the binding phenomenon of the organic formulator and fine powders. The asblended mixture still overlapped and entangled together with the remaining surfactant as shown in Figure 4A and formed irregular particles that are harmful to diefilling, compaction, and pore-filling processes during sintering. To overcome this difficulty, Figure 4B shows that the composite powder was spray dried for $30 \mathrm{~min}$ to remove the organic deflocculant from the micro-sized $\mathrm{Al}$ powder and retains the MWCNT on the surface of the Al walls. Minimal agglomerations of the MWCNTs are found in the $\mathrm{Al}$ matrix; as a result, distribution of the MWCNTs in the $\mathrm{Al}$ matrix was achieved. It is obvious that the long tubular structured MWCNTs were individually dispersed on the Al particle, and the smooth Al particle surface was retained without any change in the particle size. This was 

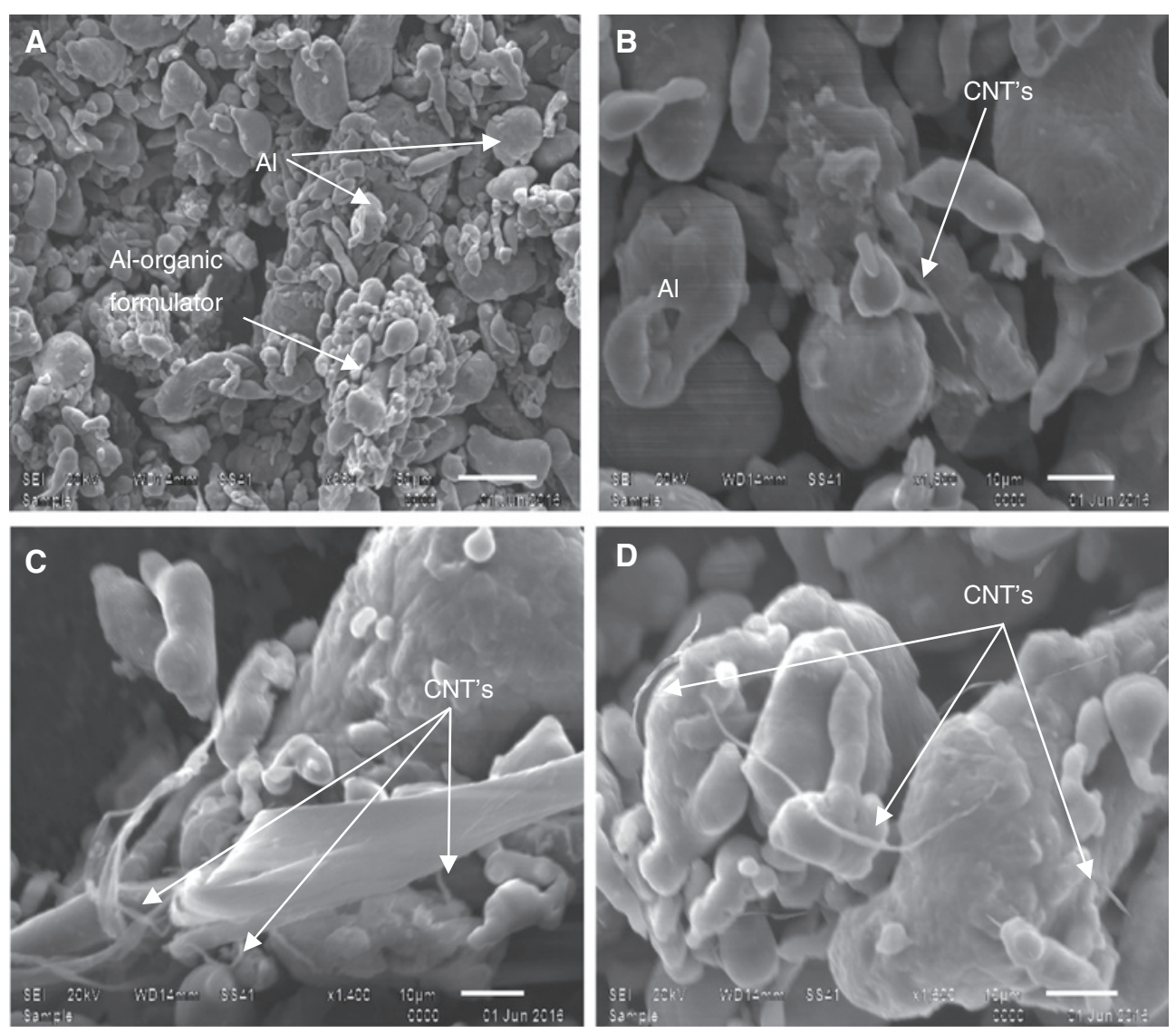

Figure 4: SEM image of (A) Al-0.75 wt. \% MWCNT-2 wt. \% organic formulator mixture produced by CTRM; (B) spray dried for 30 min, (C, D) as-produced Al- 0.75 wt. \% MWCNT composite powder.

processed by CTRM as shown in Figure 4C, D. This confirmed that the MWCNTs and Al maintain their original nature, i.e. size, shape, and morphology in the as- produced Al-0.75 wt. \% MWCNT composite powder by selecting the suitable milling media $[24,25]$. Cintas et al. [26] investigated the effect of milling media on the properties of mechanically milled $\mathrm{Al}$ powder by employing two different types of milling balls, i.e. tungsten carbide and steel, which results in the contaminated powder by WC and Co, coming from the milling balls and no remarkable change in the properties.

Figure $5 \mathrm{~A}-\mathrm{C}$ shows the SEM micrographs of the 0.75 wt. $\%$ of $\mathrm{CNT} / \mathrm{Al}$ with organic formulator mixture after various tumbling time from $2 \mathrm{~h}$ to $6 \mathrm{~h}$, and Figure 5D-F shows the magnified SEM micrographs of the white line region in $(\mathrm{A}-\mathrm{C})$, respectively. As noticed, the minimal CNT agglomerations were found in the SEM images in Figure 5 , which are bound by white dotted regions due to the used 2 wt. $\%$ of organic formulator, and the CNTs that seemed to be embedded in the $\mathrm{Al}$ matrix were also found in the image by the continuous cubic rod tumbling process at an average speed. The morphology of the 0.75 wt. \% of CNTs/Al precursors shows that the CNT bundles float on the Al powder surface with an absorbing surfactant (organic formulator) when the cubic rod tumbler milling time increases to $6 \mathrm{~h}$. These bundles are observed for a longer duration of milling due to the precursor's continuous impact on the wall surface of the cubic tumbler and rods. The CNTs dispersed on the surface of the flattened $\mathrm{Al}$ powder are shown in Figure 5D-F. With further increases in the cubic rod tumbler time to $6 \mathrm{~h}$, it is found that no cold weld is formed on the surfaces. The author noticed that the non-welding of the particles was identified while milling in the CTRM. From these results, it is evident that the effective dispersion approach for the starting precursors to obtain the CNTs implanted in the $\mathrm{Al}$ grains is essential to transfer the load and enhances the mechanical properties. The starting precursors are further warm compacted and sintered to achieve the imaginable properties of the Al/MWCNT composite.

Figure 6 shows the XRD scan of the raw MWCNT, pure $\mathrm{Al}$ powder, and as-produced Al-0.75\% MWCNT composite powder at $6 \mathrm{~h}$ of milling. It is evident that the MWCNTs 

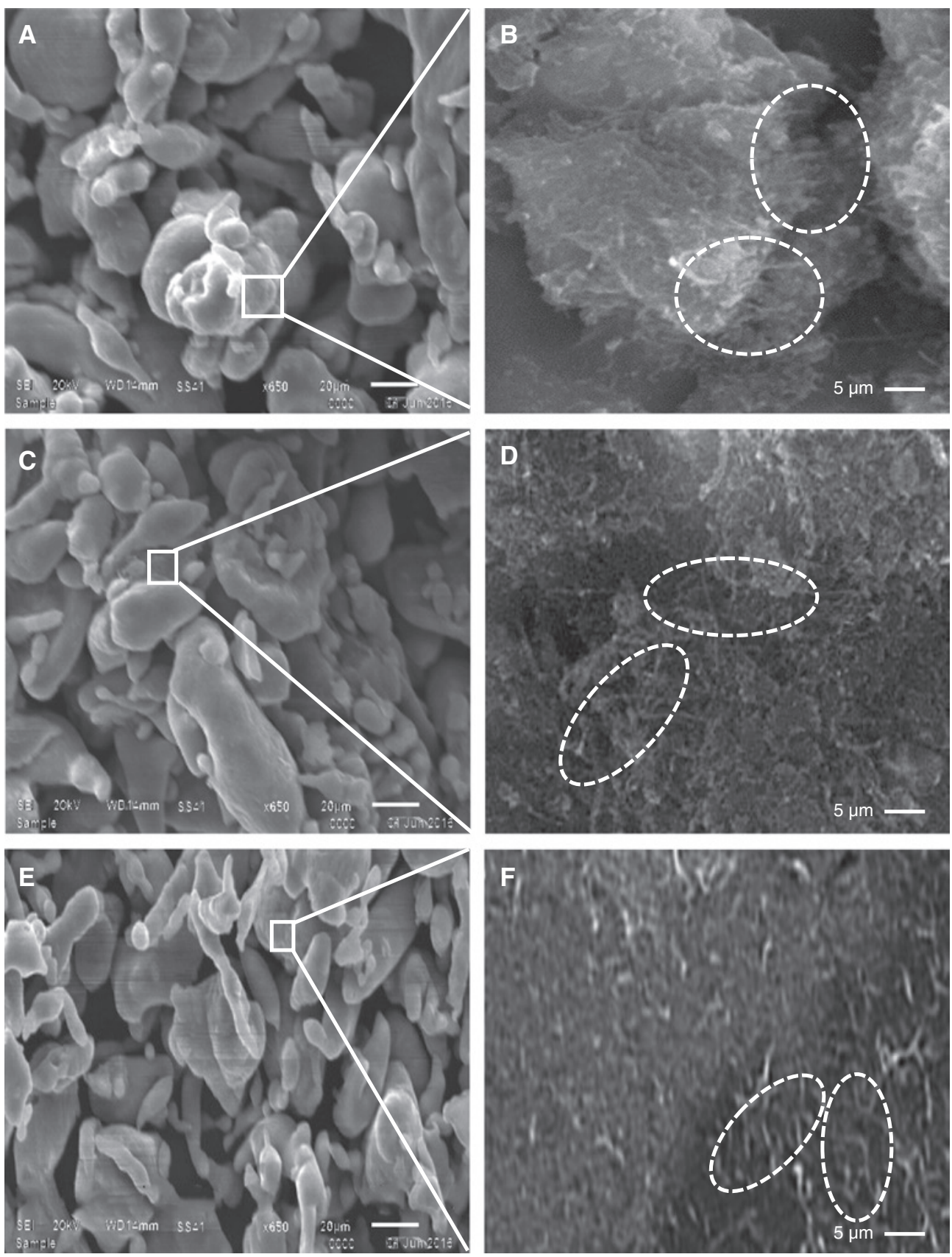

Figure 5: SEM micrographs of 0.75 wt. \% of CNT/Al with organic formulator for (A) $2 \mathrm{~h},(\mathrm{~B}) 4 \mathrm{~h},(\mathrm{C}) 6 \mathrm{~h}$ from (D), (E), (F) with the magnified image of the white line region in $(A-C)$ respectively.

show a carbon peak at an angle $2 \theta=25.75^{\circ}$ corresponding to the (002) plane spacing $=0.345 \mathrm{~nm}$. Similar XRD peaks were observed in both the pure Al powder and asproduced Al-0.75\% MWCNT composite powder with the Al peak at an angle $2 \theta=38.457^{\circ}, 38.494^{\circ}$ corresponding to the (111) planes, and carbon traces are found in the Al-CNT composite powder having no peaks due to the low detection range of the XRD and small quantity (0.75\%) of the MWCNT in the composite. The crystal size of the Al powder and CTRM composite powder was analyzed using the Scherrer equation [27]:

$$
D=\frac{0.94 \lambda}{\beta g(2 \theta) \cos (\theta)}
$$

where $\beta g(2 \theta)$ is the breadth at half maximum intensity of the peak (excluded instrumental broadening), $\lambda$ is the wavelength of the X-ray radiation, $\theta$ is the corresponding 


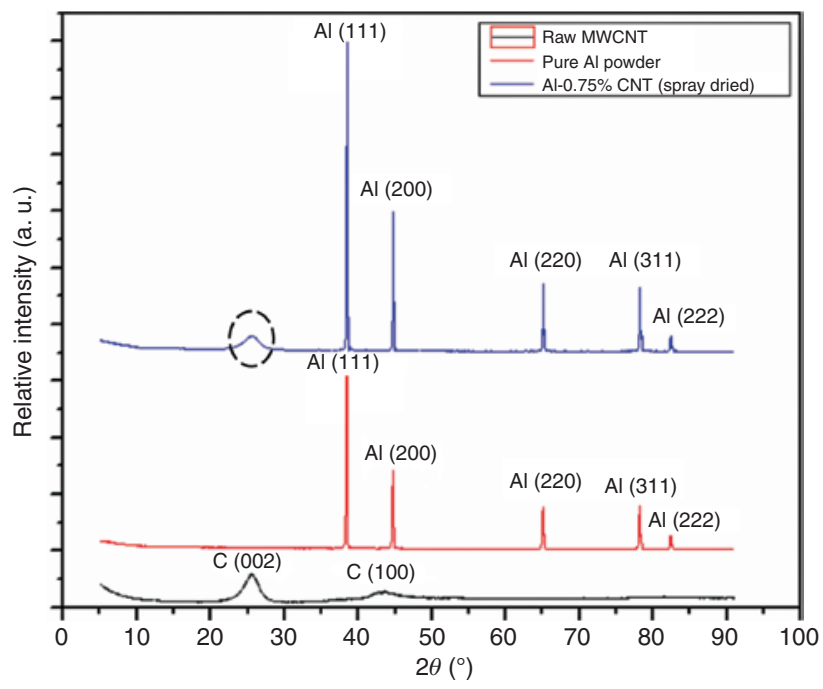

Figure 6: XRD scan of raw MWCNT, pure Al powder, and as-produced Al- $0.75 \%$ MWCNT composite precursor at $6 \mathrm{~h}$ of milling.

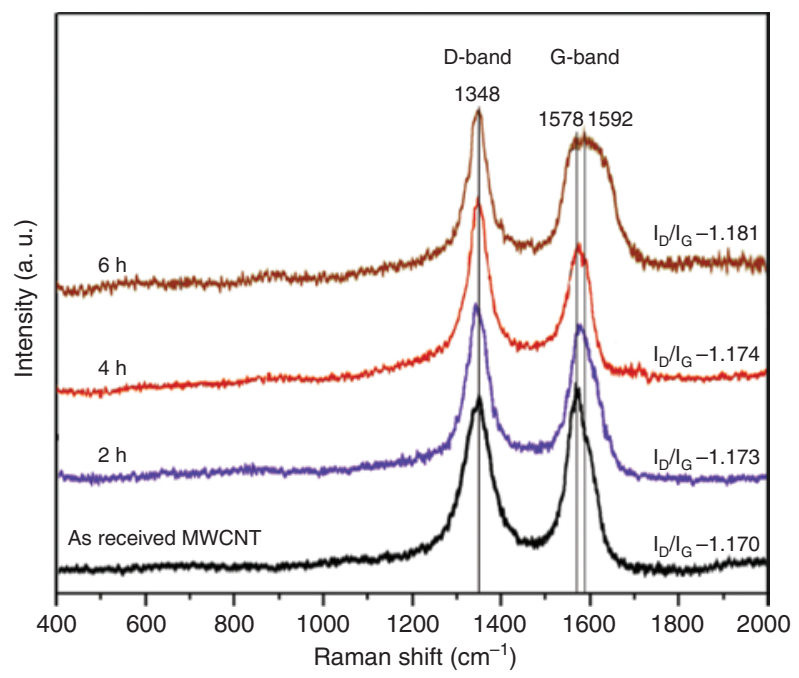

Figure 7: Raman analysis of as-received MWCNT ( 0.75 wt. \%) processed with CTRM at $2 \mathrm{~h}, 4 \mathrm{~h}$, and $6 \mathrm{~h}$.

Bragg's angle, and D is the average crystal size. The calculated crystal sizes for the Al powder and Al-0.75\% MWCNT composite powder are $19.970 \mu \mathrm{m}$ and $7.988 \mu \mathrm{m}$, respectively. This conveys that the change in the crystal size after $6 \mathrm{~h}$ of milling in the CTRM can result in good bonding between the Al-CNT particles, enhancing the powder compaction and density in the composite material.

To characterize the change in crystal structure of the CNTs, the Raman spectra was used in the studies [2, 22]. The peaks at $1348 \mathrm{~cm}^{-1}$ and $1578 \mathrm{~cm}^{-1}$ correspond to the D-band (defect) and G-band (graphite), respectively. The relative intensity between the two peaks $\left(\mathrm{I}_{\mathrm{D}} / \mathrm{I}_{\mathrm{G}}\right)$ is identified to obtain data about the internal quality of the CNTs.

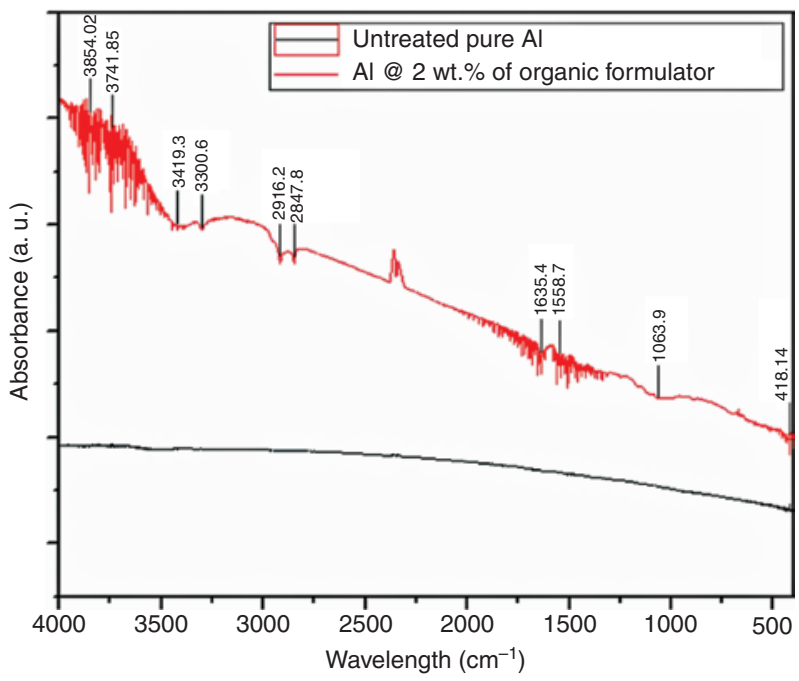

Figure 8: FTIR spectrum of the Al powder with a mixture of organic formulator.

The maximum value of $\mathrm{I}_{\mathrm{D}} / \mathrm{I}_{\mathrm{G}}$ proposed a higher defect density in the CNTs. Figure 6 shows the Raman analysis of the as-received MWCNT processed with the CTRM at $2 \mathrm{~h}, 4 \mathrm{~h}$ and $6 \mathrm{~h}$ with CNT content of 0.75 wt. \%. The $\mathrm{I}_{\mathrm{D}} / \mathrm{I}_{\mathrm{G}}$ value of the as-received MWCNT was 1.170. Blending for $2 \mathrm{~h}$ showed the same nearer value, and it revealed a minor CNT change of the dispersion process by agitators. Still, the $I_{D} / I_{G}$ value was increased, respectively, to 1.173-1.181 of the $0.75 \mathrm{wt} . \%$ CNTs for 2-h blending, 4-h blending and 6-h blending, which gives the evidence of minimal CNT change in structure by this process. In Figure 7, it is identified that the G-band peak shifts occur due to impacting stress in the CNTs by blending in the CTRM continuously for $6 \mathrm{~h}$ at moderate speed, where the CNTs impacted over the walls of the cubic surface as well as the agitators present in between the tumbler. It was also noted that the 4-h blending of the CNTs showed no peak shift in the G-band because the organic formulator ( $1 \mathrm{~g}$ of PVB as a binder, $0.5 \mathrm{~g}$ of PEG as a plasticizer, and $0.5 \mathrm{~g}$ of NN-EBS as a lubricant) acted like a buffer to reduce the impact of the agitators on the CNTs. Consequently, from the evidence on the morphology surface (Figure 4A) and the CNT structure, it suggested that a uniform dispersion of the CNTs with a large aspect ratio and a minimal structure change in the CNTs were obtained in the Al through this technique.

The functionalization of the Al powder with a mixture of the organic formulator demonstrated by the FTIR spectrum in this study, the enhancement in mixing with Al@2 wt. \% organic formulator by grouping of $1 \mathrm{~g}$ of PVB as a binder, $0.5 \mathrm{~g}$ of PEG as a plasticizer, and $0.5 \mathrm{~g}$ of NN-EBS as a lubricant (organic mixture) added into the 
as- produced Al slurry powder over the untreated $\mathrm{Al}$ may be explained in terms of the surface structural changes reinforced by the organic formulator treatment [28]. As shown in Figure 8, the FTIR spectrum of the Al@2 wt. \% organic formulator shows many additional bands compared to that of the untreated Al. The absorption band at $2847.8 \mathrm{~cm}^{-1}$ and $2916.2 \mathrm{~cm}^{-1}$ indicates a sp3 hybridized $\mathrm{C}-\mathrm{H}$ stretching vibration. The band at $1558.7 \mathrm{~cm}^{-1}$ corresponds to the $\mathrm{C}-\mathrm{H}$ stretch and bend vibrations, originating from the organic formulator-modified $\mathrm{Al}$ surface. The band at $1635.4 \mathrm{~cm}^{-1}$ indicates the presence of a carbonyl group $(\mathrm{C}=0)$. The bands at $3300.6 \mathrm{~cm}^{-1}$ and $3419.3 \mathrm{~cm}^{-1}$ are assigned to the $\mathrm{O}-\mathrm{H}$ stretch and bend vibrations of the organic formulator, respectively; the band at $1063.9 \mathrm{~cm}^{-1}$ is related to the $\mathrm{C}-\mathrm{O}$ stretch vibration, a characteristic of the organic formulator. Thus, the FTIR analysis confirms that the $\mathrm{Al}$ surface was coated with the organic formulator membrane, and also, the organic formulator membrane contains a high density of carbonyl groups $(\mathrm{C}=0)$.

Compared with the high-energy ball milling and lowenergy ball milling processes [4, 21], the present cubic tumbler rod milling process was simple and easy to use as making a starting precursor of the $\mathrm{Al} / \mathrm{CNT}$ composites, as it combined the two surface functionalizations on the $\mathrm{Al}$ and CNTs into one gathering. The $2 \mathrm{wt}$. $\%$ of organic formulator in the cubic tumbler rod milling, more of a function in decreasing the attractive force between the CNTs, decreased the impacting force of the CNTs on the rod and wall of the cube, and it also acted as a surfactant to help produce the Al powder. Therefore, the CNT dispersion can be formed on the Al flattened surface with a larger length and a minimal tubular damage than the balling milling process. Although the CRTM stuck the CNTs onto the Al surface, the process is also helpful to leave surfactants to the solution from the CNTs by the spray drying technique. As a result, a small amount of surfactant (organic formulator) in the CNT-Al powder mixture was found (Figure 4A, B). However, to eliminate the remaining surfactants (organic formulator), hot air spray drying was needed for $30 \mathrm{~min}$ in this process. Therefore, these features made the cubic tumbler rod milling process simple and effective to obtain a CNT dispersion with a large aspect ratio and minimum CNT damages, which was interesting among the present dispersion methods.

\section{Conclusion}

In summary, the Al-0.75 wt. \% CNT starting precursor was successfully synthesized by the cubic tumbler rod milling and spray drying approach by combining the organic formulator mixture, i.e. 1\% PVB as a binder, $0.5 \%$ PEG as a plasticizer, and 0.5\% NN-EBS as a lubricant. The successful functionalization of the Al powder and the MWCNTs with a mixture of organic formulator was proven by the Raman and FTIR spectrum. The interface of the Al-CNT precursor was clearly identified by the SEM results, and a few of the CNT clusters are observed on the walls of the Al matrix using this approach. Moreover, individual CNTs were incorporated in the Al matrix after $6 \mathrm{~h}$ of milling time, which appear to give minimal structural damage by maintaining the proper steps in using the organic deflocculant to bind the starting powders followed by an effective approach to obtain the untangled CNTs with a large aspect ratio. The SEM images and XRD analysis confirm that the CNTs were retained and dispersed uniformly in the as-produced composite precursor. Nevertheless, the Al-CNT starting precursor, using this approach, is subject to continuing various investigations by the authors for developing a high load transfer strengthening in the CNT/ Al composites and good improvements in the metal matrix composites reinforced with CNTs.

Acknowledgment: The authors would like to acknowledge the technical support provided by the Centre for Advanced Materials and Processing (CAM \& P) in the Central Research Laboratory at the GITAM University and Advanced Analytical Laboratory at the Andhra University. The authors also express their sincere gratitude to Prof. V. Srinivas, Department of Mechanical Engineering, GITAM Institute of Technology, GITAM University, for his support and encouragement.

\section{References}

[1] Agarwal A, Bakshi SR, Lahiri D. Carbon Nanotubes Reinforced Metal Matrix Composites, CRC Press, Taylor \& Francis Group: Boca Raton, Florida, 2010.

[2] Peng T, Chang I. J. Powtec. 2015, 284, 32-39.

[3] Simoes S, Viana F, Reis MAL, Vieira MF. J Compstruct. 2014, 108, 992-1000.

[4] Liu ZY, Xu SJ, Xiao BL, Xue P, Wang WG, Ma ZY. J. Composite A 2012, 43, 2161-2168.

[5] Esawi AMK, Mohmoud M. Farag. J. Matdes. 2007, 28, 2394-2401.

[6] Liu YM, Sung Y, Chen YC, Lin CT, Chou YH, Ger MD. Sol. Stat. Lett. 2007, 10, 101-104.

[7] Che J, Cagin T, Goddard WA. Nanotechnology 2000, 11, 65-69.

[8] Berber S, Kwon YK, Tomanek D. Phys. Rev. Lett. 2000, 84, 4613-4616.

[9] Ostovan F, Matori KA, Toozandehjani M, Oskoueian A, Yousoff HM, Yunus R, Ariff AHM, Quah HJ, Lim WF. J. Matchemphys. 2015, $166,160-166$. 
[10] He C, Zhao N, Shi C, Du X, Li J, Li H, Cui Q. Adv. Mater. 2007, 19, $1128-1132$

[11] Zhong R, Cong H, Hou P. Carbon 2003, 41, 848-851.

[12] Kwon H, Estili M, Takagi K, Miyazaki T, Kawasaki A. Carbon 2009, 47, 570-577.

[13] Choi HJ, Kwon GB, Lee GY, Bae DH. Scr. Mater. 2008, 59, 360-363.

[14] Bakshi SR, Singh V, Seal S, Agarwal A. Surf. Coat. Technol. 2009, 203, 1544-1554.

[15] Laha T, Liu Y, Agarwal A. J. Nanosci. Nanotechnol. 2007, 7, 515-524.

[16] Bakshi SR, Singh V, Balani K, McCartney DG, Seal S, Agarwal A. Surf. Coat. Technol. 2008, 202, 5162-5169.

[17] Noguchi T, Magario A, Fukuzawa S, Shimizu S, Beppu J, Seki M. Mater. Trans. 2004, 45, 602-604.

[18] Bakshi SR, Lahiri D, Agarwal A. Int. Mater. Rev. 2010, 55, 41-64.

[19] Perez-Bustamante R, Gomez-Esparza CD, Estrada-Guel I, Miki-Yoshida M, Licea-Jimenez L, Perez-Garcia SA, MartinezSanchez R. Mater. Sci. Eng. A 2009, 502, 159-163.
[20] Perez-Bustamante R, Perez-Bustamante F, Estrada-Guel I, Santillan-Rodriguez CR, Matutes-Aquino JA, Herrera-Ramirez JM, Miki-Yoshida M, Martinez-Sanchez R. J. Powtec. 2011, 212, 390-396.

[21] Esawi AMK, El Borady MA. Comput. Sci. Technol. 2008, 68, 486-492.

[22] Chen B, Li S, Imai H, Jia L, Umeda J, Takahashi M, Kondoh K. J. Matdes. 2015, 72, 1-8.

[23] Simoes S, Viana F, Reis MAL, Vieira MF. J. Compstruct. 2015, $126,114-122$.

[24] Suryanarayana C. Prog. Mater. Sci. 2001, 46(1-2), 1-184.

[25] El-Eskandarany MS, Aoki K, Suzuki K. J. Less Common Metals 1990, 167, 113-118.

[26] Cintas J, Montes JM, Cuevas FG, Herrera EJ. J. Mater. Sci. 2005, 40, 3911-3915.

[27] Choi HJ, Shin JH, Bae DH. Compos. Part A 2012, 43, 1061-1072.

[28] Shanefield DJ, Organic Additives and Ceramic Processing: With Applications in Powder Metallurgy, Ink, and Paint, Springer Science + Business Media: New York, 1995. 